\title{
PERTUMBUHAN DAN PRODUKSI JAGUNG (Zea mays. L) PADA BERBAGAI PENGELOLAAN GULMA DI KABUPATEN DELI SERDANG
}

Growth and Production of Maize (Zea mays L) in the Various of Weed Control in Distric Deli Serdang

\section{Fitria*, Edison Purba, T. Sabrina}

Program Studi Agroteknologi Fakultas Pertanian USU, Medan 20155

*Corresponding Author: E-mail : fitriasp@yahoo.com

\begin{abstract}
ABSTRAK
Kehadiran gulma pada budidaya jagung dapat menurunkan produksi jagung. Cara pengelolan gulma yang tepat diperlukan untuk menenkan pertumbuhan gulma dan diharapkan dapat meningkatkan pertumbuhan dan produksi jagung pada lahan budidaya. Penelitian ini bertujuan untuk mengetahui pengaruh herbisida terhadap cara pengelolaan gulma di kabupaten Deli Serdang. Penelitian dilaksanakan di kebun Balai Benih Induk Tanaman Palawija, Tanjung Selamat Kecamatan Sunggal Sumatera Utara pada bulan Juli-September 2013, menggunakan Rancangan Acak Kelompok (RAK) non faktorial dengan 10 perlakuan dengan 3 ulangan pengelolaan gulma. Parameter yang diamati adalah tinggi tanaman, berat 100 biji dan berat pipil per plot. Hasil penelitian menunjukkan bahwa cara pengelolaan gulma berpengaruh tidak nyata pada tinggi tanaman umur 3,6 dan 9 MST dan Bobot 100 biji namun berpengaruh nyata terhadap aplikasi herbisida dengan menggunakan calaris produksi tongkol per plot sebesar $11.47 \mathrm{~kg}$ dibandingkan dengan gulma tidak dikendalikan $3.04 \mathrm{~kg}$, dan Produksi Pipil Per Plot.
\end{abstract}

Kata kunci : pengelolaan gulma, herbisida, jagung

\section{PENDAHULUAN}

Jagung (Zea mays L.) merupakan tanaman pangan dunia yang terpenting selain gandum dan padi sebagai karbohidrat utama. Manfaat jagung tidak hanya sebagai bahan pangan, tetapi juga bahan pakan dan bahan industri lainnya. Diperkirakan lebih dari $55 \%$ kebutuhan jagung dalam negeri digunakan untuk pakan $30 \%$ untuk konsumsi pangan selebihnya untuk kebutuhan industri lainnya dan bibit, hal ini menyebabkan kebutuhan akan jagung terus mengalami peningkatan (Kasryno dkk., 2007).

Produksi jagung secara nasional tahun 2010 mencapai 17,84 juta ton pipilan kering. Dari beberapa Kabupaten penghasil jagung di Sumatera Utara yang terbesar adalah Kabupaten Karo, Simalungun, Dairi, Deli Serdang (Dinas Pertanian Sumatera Utara,
2010). Produksi nasional jagung terbesar di Sumatera Utara salah satunya di Kabupaten Deli Serdang luas panen 20,23 ha, memiliki produksi 101,93 ton, rata-rata produksi 50,16 kw/ha (BPS, 2010).

Cara persiapan lahan dengan teknik tanpa olah tanah (TOT) atau no tillage adalah sistim pengolahan tanah yang merupakan adopsi sistim perladangan dengan memasukkan konsep pertanian modern. Tanah dibiarkan tidak terganggu, kecuali alur kecil atau lubang untuk penempatan benih atau bibit. Sebelum tanam sisa tanaman atau gulma dikendalikan sedemikian rupa sehingga tidak mengganggu penempatan benih atau bibit tersebut. Pengelolaan gulma, terutama alang-alang biasanya menggunakan herbisida sistemik yang ramah lingkungan. Sisa-sisa tanaman ini kemudian dimanfaatkan untuk menutupi permukaan 
tanah dan perakaran yang mati dibiarkan tinggal di dalam tanah. Seresah tanaman yang mati dan dihamparkan dipermukaan tanah ini dapat berperan sebagai mulsa dan menekan pertumbuhan gulma baru dan pada akhirnya dapat memperbaiki sifat dan tata air tanah (Rauf, 2005).

Pengolahan tanah maksimum atau pengolahan tanah sempurna (full tillage). Ciri utama pengolahan tanah sempurna ini antara lain adalah membabat bersih, membakar atau menyingkirkan sisa tanaman atau gulma serta perakarannya dari areal penanaman serta melalukan pengolahan tanah lebih dari satu kali baru ditanami. Dengan pengolahan tanah maksimum ini permukaan tanah menjadi bersih, rata dan bongkahan tanah menjadi halus. Oleh karena itu perlu dicari metode yang lebih efektif dan efisien melalui pertanian tanpa olah tanah (zero tillage) dan sedikit mungkin olah tanah hanya pada jalur lubang tanam tempat benih (minimum tillage) sehingga erosi tanah dapat diperkecil, aliran permukaan tanah dapat ditekan, evavorasi lebih sedikit, air tersedia lebih banyak (Bangun dan Karama, 1991).

Tanpa pengelolaan gulma, pertumbuhan tanaman jagung tertekan sehingga hasilnya rendah. Oleh sebab itu, pengelolaan gulma mutlak diperlukan apalagi pada budidaya tanpa olah tanah. Pengelolaan gulma dapat dilakukan dengan cara manual seperti penyiangan menggunakan cangkul atau bajak, atau secara mekanis menggunakan alat, mesin, dan secara kimiawi menggunakan herbisida. Dari segi teknis, penyiangan dengan herbisida tidak berbeda dengan penyiangan secara mekanis. Takaran dan jenis herbisida yang digunakan bergantung pada jenis gulma, kepadatan gulma, dan anjuran penggunaan masing - masing herbisida (Akil dan Dahlan, 2005).

Gulma pada tanaman jagung dengan persiapan lahan tanpa olah tanah dikendalikan dengan herbisida Sebelum jagung ditanam, herbisida disemprotkan untuk mematikan gulma yang tumbuh di areal pertanaman. setelah jagung tumbuh, gulma masih perlu dikendalikan untuk melindungi tanaman. Pengelolaan dapat dilakukan dengan cara penyiangan dengan tangan, penggunaan alat mekanis, dan penyemprotan herbisida. (Fadhly dan Tabri, 2011).

Pengendalian gulma dengan menggunakan senyawa kimia akhir-akhir ini sangat diminati, terutama untuk lahan pertanian yang cukup luas. Senyawa kimia yang digunakan untuk pengendali gulma ini dikenal dengan " herbisida" dapat mengendalikan gulma tanpa menggangu tanaman pokoknya (Brandli dan Reinacher, 2012).

Menurut Astri (2012), Herbisida nonselektif bisa digunakan untuk mengendalikan gulma pada tanaman jagung, khususnya herbisida kontak seperti paraquat. Teknik pengaplikasiannya dapat dilakukan dengan teknik direct spray yang menggunakan sungkup atau corong agar tidak mengenai tanaman jagung. Namun dewasa ini telah ada beberapa jenis herbisida yang bisa diaplikasikan langsung keatas tanaman jagung Herbisida selektif ini mempunyai bahan aktif campuran atrazin dan mesotrion serta berbahan aktif tunggal ametrin yang dapat diaplikasikan pada saat jagung berumur 7 sampai 14 hari dengan kondisi tanah yang lembab, dan jagung mempunyai 3-4 helai daun. Keuntungan lainnya herbisida ini selektif dan tidak meracuni tanaman jagung, dengan dosis 1,5 liter/ha dan volume semprot 400-600 liter per hektar. Penggunaan herbisida selektif pada tanaman jagung memberi keuntungan kepada petani secara ekonomis dibandingkan dengan penyiangan secara manual sedangkan keuntungan lainnya adalah hemat waktu, tenaga serta hasil panen yang lebih baik dikarenakan tidak terjdi persaingan kebutuhan unsur hara antara tanaman jagung dengan gulma.

Penelitian ini bertujuan untuk mengetahui pengaruh herbisida terhadap cara pengelolaan gulma di kabupaten Deli Serdang. 


\section{BAHAN DAN METODE}

Penelitian dilaksanakan di kebun Balai Benih Induk Tanaman Palawija, Tanjung Selamat, Kecamatan Sunggal, Kabupaten Deli Serdang, Sumatera Utara dengan ketinggian tempat $\pm 25 \mathrm{~m}$ diatas permukaan laut (dpl), penelitian dilaksanakan pada bulan Juli - September 2013. Penelitian ini menggunakan Rancangan Acak Kelompok (RAK) non faktorial dengan 10 Perlakuan dengan 3 ulangan yaitu T1 (olah tanah sempurna, 21 dan 42 HST aplikasi paraquat) , T2 (olah tanah sempurna, 21 dan 42 HST aplikasi calaris), T3 (olah tanah sempurna,

\section{HASIL PEMBAHASAN}

\section{Tinggi Tanaman}

Tabel 1 menunjukkan bahwa perlakuan cara pengelolaan gulma tinggi tanaman tertinggi diperoleh pada perlakuan T2 dan T7 yaitu berkisar 57,33$57,89 \mathrm{~cm}$ pada pengamatan 3 MST , 163,45 - 148,56 cm pada pengamatan 6 MST dan 221,00-217,33 cm pada pengamatan 9 MST, sedangkan tinggi tanaman terendah terdapat pada perlakuan T10 yaitu $39,89 \mathrm{~cm}$ pada
21 dan 42 HST disiangi), T4 (olah tanah sempurna, 14 HST disiangi), T5 (olah tanah sempurna gulma tidak dikendalikan), T6 (tanpa olah tanah 21 dan 42 HST aplikasi paraquat), T7 (tanpa olah tanah 21 dan 42 HST aplikasi calaris), T8 (tanpa olah tanah 21 dan 42 HST disiangi), T9 (tanpa olah tanah 14 HST disiangi), T10 (tanpa olah tanah gulma tidak dikendalikan). Peubah amatan dalam penelitian ini adalah tinggi tanaman, Produksi tongkol per plot, Bobot kering 100 Biji, Produksi pipil per plot. pengamatan 3 MST, $122,89 \mathrm{~cm}$ pada pengamatan 6 MST, dan 194,56 cm pada pengamatan 9 MST. Tinggi tanaman jagung tidak berbeda nyata terhadap pengelolaan gulma. Meskipun tidak berpengaruh nyata tetapi persiapan lahan dengan tanpa olah tanah mampu memperbaiki sifat dan tata air tanah (Rauf, 2005).

Tabel 1. Tinggi Tanaman jagung pada berbagai teknik pengendalian gulma pada umur 3,6 dan 9 MST di Kabupaten Deli Serdang.

\begin{tabular}{lccc}
\hline \multicolumn{1}{c}{ Perlakuan } & 3 MST & 6 MST & 9 MST \\
\hline & ----------- \\
T1 (OTS 21 dan 42 HST aplikasi paraquat) & 55.22 & 163.45 & 217.33 \\
T2 (OTS 21 dan 42 HST aplikasi Calaris) & 57.33 & 139.78 & 215.67 \\
T3 (OTS 21 dan 42 HST disiangi) & 54.56 & 139.89 & 216.33 \\
T4 (OTS 14 HST disiangi) & 57.89 & 148.44 & 221.00 \\
T5 (OTS dan gulma tidak dikendalikan) & 52.78 & 148.56 & 205.56 \\
T6 (TOT 21 dan 42 HST aplikasi paraquat) & 42.33 & 126.56 & 194.33 \\
T7 (TOT 21 dan 42 HST aplikasi Calaris) & 40.78 & 129.67 & 195.33 \\
T8 (TOT 21 dan 42 HST disiangi) & 51.67 & 141.11 & 210.33 \\
T9 (TOT 14 HST disiangi) & 50.67 & 134.78 & 200.00 \\
T10(TOT dan gulma tidak dikendalikan) & 39.89 & 122.89 & 194.56 \\
\hline
\end{tabular}

Keterangan : Angka yang diikuti oleh huruf yang sama pada kolom yang sama tidak berbeda nyata pada taraf 5\% menurut uji beda rataan DMRT (Duncan Multiple Range Test). 
Produksi Tongkol Per Plot (Kg)

Tabel 2. Produksi Tongkol Per Plot pada berbagai pengendalian gulma di Kabupaten Deli Serdang.

\begin{tabular}{lc}
\hline \multicolumn{1}{c}{ Perlakuan } & Tongkol per Plot $(\mathrm{kg})$ \\
\hline T1 (OTS 21 dan 42 HST aplikasi paraquat) & $11.40 \mathrm{a}$ \\
T2 (OTS 21 dan 42 HST aplikasi Calaris) & $11.47 \mathrm{a}$ \\
T3 (OTS 21 dan 42 HST disiangi) & $11.07 \mathrm{a}$ \\
T4 (OTS 14 HST disiangi) & $10.27 \mathrm{ab}$ \\
T5 (OTS dan gulma tidak dikendalikan) & $9.13 \mathrm{ab}$ \\
T6 (TOT 21 dan 42 HST aplikasi paraquat) & $4.03 \mathrm{~d}$ \\
T7 (TOT 21 dan 42 HST aplikasi Calaris) & $4.73 \mathrm{~cd}$ \\
T8 (TOT 21 dan 42 HST disiangi) & $7.70 \mathrm{bc}$ \\
T9 (TOT 14 HST disiangi) & $6.00 \mathrm{~cd}$ \\
T10(TOT dan gulma tidak dikendalikan) & $4.03 \mathrm{~d}$ \\
\hline
\end{tabular}

Keterangan : Angka yang diikuti oleh huruf yang sama pada kolom yang sama tidak berbeda nyata pada taraf $5 \%$ menurut uji beda rataan DMRT (Duncan Multiple Range Test).

Tabel 2 menunjukkan tinggi produksi tongkol per plot tertinggi diperoleh pada perlakuan $\mathrm{T} 1$ dan $\mathrm{T} 2$ yaitu 11,40 - 11,47 $\mathrm{kg}$ dan terendah diperoleh pada perlakuan T6 dan T7 berkisar 4,034,73 kg. Hal ini menunjukkan bahwa aplikasi paraquat dan calaris mampu memberikan hasil tinggi sesuai dengan pernyataan (Astri, 2012). Herbisida nonselektif bisa digunakan untuk mengendalikan gulma pada tanaman jagung, khususnya herbisida kontak seperti paraquat. Teknik pengaplikasiannya dapat dilakukan dengan direct spray yang menggunakan sungkup atau corong agar tidak mengenai tanaman jagung.

Ada Jenis herbisida diaplikasikan langsung keatas tanaman jagung, aktif campuran atrazin dan mesotrion serta berbahan aktif tunggal ametrin yang dapat diaplikasikan pada saat jagung berumur 7 sampai 14 hari dan jagung mempunyai 34 helai daun. Keuntungan lainnya herbisida ini selektif dan tidak meracuni tanaman jagung. Penggunaan herbisida selektif pada tanaman jagung memberi keuntungan kepada petani secara ekonomis dibandingkan dengan penyiangan secara manual sedangkan keuntungan lainnya adalah hemat waktu, tenaga serta hasil panen yang lebih baik dikarenakan tidak terjadi persaingan kebutuhan unsur hara antara tanaman jagung dengan gulma.

Tabel 3. menunjukkan produksi pipil per plot tertinggi diperoleh pada perlakuan T1 dan T3 yaitu 9,47-9,43 kg dan terendah diperoleh pada perlakuan T10 dan T6 berkisar 3,07-2,93 kg. Hal ini menunjukkan olah tanah sempurna dengan tanpa olah tanah mampu berpengaruh terhadap pengelolaan gulma hal ini menunjukan bahwa olah tanah sempurna menunjukkan hasil pipil tinggi sesuai dengan pernyataan (Bangun dan Karama, 1991) pengolahan tanah sempurna antara lain dengan membabat bersih, membakar atau menyingkirkan sisa tanaman atau gulma serta perakarannya dari areal penanaman serta melakukan pengolahan tanah lebih dari satu kali baru ditanami. Dengan pengolahan tanah maksimum ini permukaan tanah menjadi bersih, rata dan bongkahan tanah menjadi halus. 
Produksi Pipil Per plot (kg)

Tabel 3. Produksi Pipil Per Plot pada berbagai pengendalian gulma di Kabupaten Deli Serdang.

\begin{tabular}{lc}
\hline \multicolumn{1}{c}{ Perlakuan } & Pipil Per Plot $(\mathrm{kg})$ \\
\hline T1 (OTS 21 dan 42 HST aplikasi paraquat) & $9.47 \mathrm{a}$ \\
T2 (OTS 21 dan 42 HST aplikasi Calaris) & $8.77 \mathrm{a}$ \\
T3 (OTS 21 dan 42 HST disiangi) & $9.43 \mathrm{a}$ \\
T4 (OTS 14 HST disiangi) & $8.00 \mathrm{ab}$ \\
T5 (OTS dan gulma tidak dikendalikan) & $7.30 \mathrm{ab}$ \\
T6 (TOT 21 dan 42 HST aplikasi paraquat) & $3.07 \mathrm{~d}$ \\
T7 (TOT 21 dan 42 HST aplikasi Calaris) & $3.70 \mathrm{~cd}$ \\
T8 (TOT 21 dan 42 HST disiangi) & $5.90 \mathrm{bc}$ \\
T9 (TOT 14 HST disiangi) & $4.70 \mathrm{~cd}$ \\
T10(TOT dan gulma tidak dikendalikan) & $2.93 \mathrm{~d}$ \\
\hline
\end{tabular}

Keterangan : Angka yang diikuti oleh huruf yang sama pada kolom yang sama tidak berbeda nyata pada taraf $5 \%$ menurut uji beda rataan DMRT (Duncan Multiple Range Test).

Bobot 100 Biji (g)

Tabel 4. Bobot 100 Biji jagung pada beberapa perlakuan pengendalian gulma di Kabupaten Deli Serdang

\begin{tabular}{lc}
\hline \multicolumn{1}{c}{ Perlakuan } & Bobot 100 biji $(\mathrm{g})$ \\
\hline T1 (OTS 21 dan 42 HST aplikasi paraquat) & 34.63 \\
T2 (OTS 21 dan 42 HST aplikasi Calaris) & 32.54 \\
T3 (OTS 21 dan 42 HST disiangi) & 33.22 \\
T4 (OTS 14 HST disiangi) & 31.62 \\
T5 (OTS dan gulma tidak dikendalikan) & 31.01 \\
T6 (TOT 21 dan 42 HST aplikasi paraquat) & 28.54 \\
T7 (TOT 21 dan 42 HST aplikasi Calaris) & 29.42 \\
T8 (TOT 21 dan 42 HST disiangi) & 30.59 \\
T9 (TOT 14 HST disiangi) & 30.53 \\
T10(TOT dan gulma tidak dikendalikan) & 28.39 \\
\hline
\end{tabular}

Keterangan : Angka yang diikuti oleh huruf yang sama pada kolom yang sama tidak berbeda nyata pada taraf 5\% menurut uji beda rataan DMRT (Duncan Multiple Range Test).

Tabel 4 menunjukkan Bobot kering 100 biji tertinggi diperoleh pada perlakuan T1 dan T3 yaitu 34,63-33,22 g dan terendah diperoleh pada perlakuan T6 dan T10 berkisar 28,54-28,39 $\mathrm{g}$ hal ini menunjukkan tidak ada pengaruh nyata pada pelakuan persiapan lahan dan pengelolaan gulma.

\section{SIMPULAN}

Pengendalian gulma pada tanamana jagung pada berbagai perlakuan berpengaruh nyata terhadap produksi tongkol per plot yaitu sebesar $11.47 \mathrm{~kg}$ dibandingkan gulma tanpa dikendalikan yaitu hanya $4.03 \mathrm{~kg}$. Pertumbuhan dan produksi jagung dilihat dari aplikasi paraquat dan calaris memberikan produksi tinggi meskipun dengan penyiang produksi tinggi tetapi tidak menghemat biaya dan waktu disarankan petani mengendalikan gulma dengan herbisida kontak maupun sistemik untuk menggantikan teknik pengelolaan gulma secara manual. 


\section{DAFTAR PUSTAKA}

Akil, M dan H.A. Dahlan. 2009. Budi Daya Jagung dan Diseminasi Teknologi. Balai Penelitian Tanaman Serealia,Maros.

Astri. A., 2012. Teknik Pengendalian Gulma Pada Tanaman jagung. BPTP Kalimantan Tengah. Badan Litbang Pertanian. Kementrian Pertanian.

Bangun, P. dan A. S. Karama. 1991. Tanaman Pangan dan Metode Tanpa Olah Tanah dan Diolah Minimum. Jurnal Penelitian dan Pengembangan Pertanian, 10 (4) Hal $61-68$.

BPS. 2010. Produksi Padi, Jagung, Dan Kedelai (Angka Sementara Tahun 2009 Dan Angka Ramalan I Tahun 2010). Biro Pusat Statistik, JakartaIndonesia.

Brandli dan Reinacher, 2012. Brandli, D., S. Reinacher. 2012. Toleransi Glifosat dalam Kanola PRG Gen GOX modifikasi. Diakses dari http://isaaa.org/kc/cropbiotechupdat e/files/bahasa. pdf.

Dinas Pertanian Sumatera Utara, 2010. Produksi Jagung Sumatera Utara. Dinas Pertanian Provinsi Sumatera Utara.

Fadhly, A.F. dan F. Tabri. 2011. Pengendalian Gulma pada Pertanaman Jagung. Balai Penelitian Tanaman Serealia, Maros.

Kasryno, F., E. Pasandaran, Suyamto dan M.O. Adyana. 2007. Gambaran Umum Ekonomi Jagung Indonesia Teknik Produksi dan Pengembangan. Pusat Penelitian dan Pengembangan Tanaman Pangan, Bogor, p 474-497.

Rauf. A, 2005. Teknik Konservasi Tanah dan Air. Diktat Bahan Kuliah. Fakultas Pertanian, Jurusan Ilmu Tanah. USU, Medan 